\title{
The Mutated Acetolactate Synthase Gene from Rice as a Non-Antibiotic Selection Marker for Transformation of Bamboo Cells
}

\author{
Shinjiro Ogita*, Nanaka Kikuchi, Taiji Nomura, Yasuo Kato \\ Laboratory of Plant and Cell Engineering, Department of Biotechnology, Toyama Prefectural University, Toyama, Japan. \\ Email: *ogita@pu-toyama.ac.jp
}

Received October $12^{\text {th }}, 2011$; revised November $26^{\text {th }}, 2011$; accepted December $27^{\text {th }}, 2011$

\begin{abstract}
Previously, we developed a particle bombardment-mediated transformation protocol in Phyllostachys nigra bamboo by expressing hygromycin phosphotransferase gene (HPT) and neomycin phosphotransferase II gene (NPT II). Although these marker genes could introduce to several tissue cultured organs (e.g. leaves, buds, and calli) of Phyllostachs bamboo species, some organs showed a high susceptibility and/or a low selectivity to hygromycin and kanamycin. In this report, therefore, we describe advantages and technical details for generating stable transgenic bamboo cells using the particle bombardment method with the mutated-acetolactate synthase gene $(m A L S)$ from rice (W548L/S627IOsALS) as a non-antibiotic selection marker. A facile and efficient transformation was achieved with the $m A L S$ gene and enhanced fluorescent protein gene ( $m$ Cherry). Approximately 490 and $1400 \mathrm{mCherry}$-expressing cells/dish/shot in average were observed in both $P$. bambusoides and $P$. nigra under fluorescent stereo-microscope. Stable transgenic bamboo cell lines were generated in a selection medium supplemented with $0.1 \mu \mathrm{M}$ of bispyribac-sodium (BS) as ALS inhibitor. The integration of $m A L S$ gene was identified by in vivo ALS enzyme assay and a PCR-restriction fragment length polymerphism (RFLP) based detection procedures.
\end{abstract}

Keywords: Bamboo; Mutated Acetolactate Synthase Gene; Particle Bombardment; Suspension Culture

\section{Introduction}

Acetolactate synthase (ALS: EC 2.2.1.6) is the common enzyme in the biosynthetic pathway of the branchedchain amino acids leucine, isoleucine, and valine. A mutatedALS $(m A L S)$ gene was isolated from pyrimidinyl carboxy herbicide (Pyriminobac, pyrithiobac-sodium and bispiribac-sodium)-resistant somaclonal variation rice cells and found to have a single amino acid change from serine to isoleucine in a conserved region [1]. Recently, it was developed that the $m A L S$ gene can be used as a new selectable marker to produce transgenic plants such as Arabidopsis [2], rice [3-5], soybean [6], and wheat [7]. These contributions allow us to overcome many difficulties for the selection of transformants of the target plants.

It is very important contribution to improve a new vector system/plural vector choices as powerful tools for understanding physiological/ molecular biological events and/or engineering complex biosynthetic pasway(s) of target plant cells by introducing multiple genes. At present, however, little information is available concerning

"Corresponding author. the transformation of bamboo plants. In order to investigate/improve biosynthetic pathway(s) of bamboo plants, it is essential to develop an efficient transformation protocol for a model cell culture system.

Previously, we developed a cell culture system [8] and a particle bombardment-mediated transformation protocol in Phyllostachys nigra bamboo by expressing hygromycin phosphotransferase gene (HPT) and neomycin phosphotransferase II gene (NPT II) [9]. Although this system has been currently used for a regular transformation technique of bamboo cells in our researches, there is scope for improvement such as a high toxicity and/or a low selectivity of antibiotics in some organs (e.g. leaves and buds) or cell lines as shown in Figure 1(A). In this report, therefore, we described advantages and technical details for generating stable transgenic bamboo cells using the particle bombardment method with $m A L S$ gene as a non-antibiotic selection marker.

\section{Materials and Methods}

\subsection{Bamboo Cell Cultures}

Callus cultures of two bamboo species, both P. bam- 


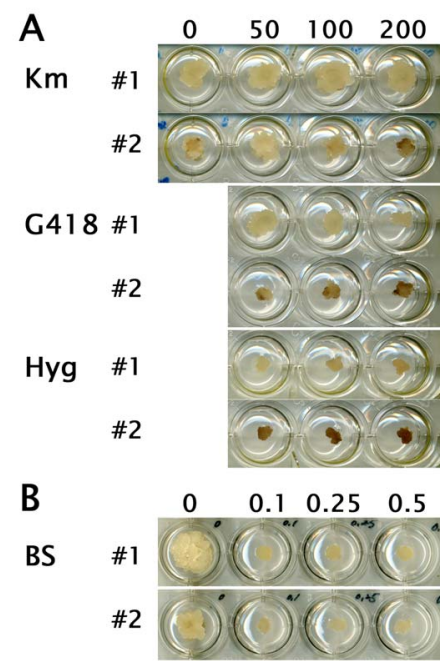

Figure 1. Effects of antibiotics and BS on the proliferation of bamboo cells; (A) Antibiotics condition; (B) BS condition. \#1: P. nigra, \#2: P. bambusoides. 50, 100, $200 \mathrm{mg} / \mathrm{l}$ of $\mathrm{Km}$, G418, and Hyg; $0.1,0.25$, and $0.5 \mu \mathrm{M}$ of $\mathrm{BS}$ were added to the medium, respectively.

busoides and P. nigra, were induced from young bamboo shoots as described by Ogita [8]. Suspension cell cultures were also generated as described by Ogita et al. [9]. MSp680 medium supplemented with $680 \mathrm{mg} \cdot l^{-1} \mathrm{KH}_{2} \mathrm{PO}_{4}$ and $10 \mu \mathrm{M}$ 4-amino-3,5,6-trichloropyridine-2-carboxylic acid (Picloram) was used for the basal medium.

In order to maintain their stable morphology and synchronous growth under suspension culture condition, sedimented cell volume (SCV) was adjusted every 2 weeks. Briefly, $2.5 \mathrm{ml}$ cells in SCV were initially transferred to $100 \mathrm{ml}$ liquid MSp680 medium, i.e. $2.5 \%(\mathrm{v} / \mathrm{v})$ initial cell density, in a 300-ml flask. The flasks were placed on a rotary shaker with a speed of $100 \mathrm{rpm}$ for 2 weeks in the dark at $25^{\circ} \mathrm{C}$. The SCV was measured by holding a liquid suspension cells for 15 minutes in a 50 $\mathrm{ml}$ centrifugation tube graduated in milliliters. In order to investigate susceptibilities to antibiotics, $0,50,100$, and $200 \mathrm{mg} / \mathrm{l}$ of kanamycin (Km), geneticin (G418), and hygromycin (Hyg) were added to the MSp680 medium. Two-ml each of resulted media were poured into a well of 12-well microplate. A portion of callus (ca. $50 \mathrm{mg}$ fresh weight) was transferred to each well and cultured for 3 weeks. All cultures were incubated in the dark at $25^{\circ} \mathrm{C}$.

\subsection{Vectors for Transformation}

The pBIH1-IG vector [10], carrying the hygromycin phosphotransferase gene (HPT) and the neomycin phosphotransferase II gene (NPT II) was used as the backbone vector. The original intron-GUS sequence of the pBIH1IG at the $X b a$ I and $S a c$ I sites located between the cauli- flower mosaic virus 35S promoter (CaMV35Sp) and the nopaline synthase terminator (NOSt) was replaced with a red florescent protein gene ( $m$ Cherry) originated from the pmCherry vector (Clontech Laboratories, Inc., USA). The pBIH1-RFP vector [9] was used as a control vector for transient transformation of bamboo cells. The cassette (CaMV35Sp::mCherry::NOSt) was amplified from the pBIH1-RFP and introduced to the multi-cloning site of pSTARA (R-4) vector harboring the mutated ALS gene (W548L/S627IOsALS) under the control of ALS promoter and ALS terminator (Kumiai Chemical Industry Co., Ltd., Japan). The resulted pSTARA-RFP vector was used for stable transformation of bamboo cells.

\subsection{Transformation}

Gold particles, $0.6 \mu \mathrm{m}$ in diameter, were coated with the plasmid DNA according to Ogita et al. [9]. The bombardment was carried out once using the Biolistic Particle Delivery System (PDS-1000/He, Bio-Rad, USA) at $1100 \mathrm{psi}$ of helium pressure. Seven to fourteen days after bombardment, the cells were transferred to a selection medium supplemented with $0.1 \mu \mathrm{M}$ of bispyribac-sodium (BS) as an ALS inhibitor. They were then subcultured at 2- to 4-week intervals onto fresh selection medium.

\subsection{Detection of Transformants}

Transient expression of $m$ Cherry gene in bombarded bamboo cells was observed under a fluorescence stereo microscope (SteREO Lumar.V12, Zeiss, Germany).

The transformed suspension cells were collected and observed using a laser scanning microscope (LSM510 META, Zeiss, Germany) for characterization of the $m$ Cherry-expressing cells. Genomic DNA was extracted from transformed cells with an ISOPLANT II kit (Nippon gene, Japan) and subjected to PCR analysis using two sets of gene specific primers; for $m A L S, 5$ '-TGGTCTGGGCGCAATGGGATTTG-3' and 5'-CAAC-AAGTATGGCCCTGGAGTCTC-3'; for mCherry, 5'-CCACTACTTGAAGCTGTCC-3' and 5'-GGGGAGTCCCTTGTACAGCTCGTCCATGC-3'. PCR was performed in a $20 \mu 1$ reaction mixture containing $2 \mu \mathrm{l}$ of $2 \mathrm{mM}$ dNTP, $2 \mu \mathrm{l}$ of $10 \times$ Blend Taq buffer, 0.5 unit of Blend Taq polymerase (Toyobo, Japan), $1 \mu \mathrm{l}$ of primers $(10 \mu \mathrm{M})$ and $100 \mathrm{ng}$ of template genomicDNA (10 ng of template in case of vector control). The amplification reaction was carried out under the conditions of up to 40-cycle of denaturation at $96^{\circ} \mathrm{C}$ for $30 \mathrm{~s}$, annealing at $60^{\circ} \mathrm{C}$ for $30 \mathrm{~s}$ and extension at $72^{\circ} \mathrm{C}$ for $1 \mathrm{~min}$. For detection of $m A L S$ gene, the amplified DNA fragment (388-bp) was treated with $M f e I$ (New England Biolabs, USA) in a $10 \mu \mathrm{l}$ reaction mixture containing $1 \mu \mathrm{l}$ of of $10 \times$ FD Green buffer, $1 \mu \mathrm{l}$ of $\mathrm{MfeI}$ (20 unit) and $5 \mu \mathrm{l}$ of template DNA 
at $37^{\circ} \mathrm{C}$ for $30 \mathrm{~min}$. The restriction fragments $(194$ and 198-bp) which were derived from $m A L S$ were identified. The resulted DNAs were detected with ethidium bromide staining after agarose gel electrophoresis.

In vivo ALS assay was performed using 24-well micro plate according to the procedure of Kawai et al. [2] with minor modifications. Bamboo cultured cells (ca. $0.2 \mathrm{~g}$ fresh weight) were put into a well and incubated in $1 \mathrm{ml}$ of $25 \%$ Murashige and Skoog salt medium containing 10 $\mathrm{mM}$ of sodium pyruvate as a substrate, $500 \mu \mathrm{M} 1,1$ cyclopropanedicarboxylic acid (CPCA) as a ketol-acid reductoisomerase (KARI) inhibitor, and w/wo $0.1 \mu \mathrm{M}$ of BS as ALS inhibitor. The micro plate was incubated at $25^{\circ} \mathrm{C}$ in the dark for $24-48 \mathrm{hr}$. After the incubation, cells were transferred into a $1.5 \mathrm{ml}$ tube. To determine ALS activity, $500 \mu 1$ of milliQ water was added to the samples and they were heated to $60^{\circ} \mathrm{C}$ for $5 \mathrm{~min}$ and then kept for $25 \mathrm{~min}$ at room temperature. Aliquots of $100 \mu \mathrm{l}$ were taken and mixed with $10 \mu \mathrm{l}$ of $5 \%(\mathrm{w} / \mathrm{v}) \mathrm{H}_{2} \mathrm{SO}_{4}$. The acidified solutions were incubated at $60^{\circ} \mathrm{C}$ for $30 \mathrm{~min}$ to facilitate the decarboxylation of acetolactate to acetoin. Then, $50 \mu \mathrm{l}$ of $0.5 \%(\mathrm{w} / \mathrm{v})$ creatin and $50 \mu \mathrm{l}$ of $5 \%(\mathrm{w} / \mathrm{v})$ 1-naphthol dissolved in $2.5 \mathrm{~N} \mathrm{NaOH}$ were added to the samples. To allow color development, the samples were incubated at $37^{\circ} \mathrm{C}$ for $30 \mathrm{~min}$. The reddish resultant reaction mixtures were judged as acetoin accumulation.

\section{Results and Discussion}

\subsection{Effects of Antibiotics and BS}

We preliminary investigated the susceptibility to antibiotics in P. bambusoides and P. nigra cell lines (Figure 1(A)). P. nigra cell line which is our regular cell line (\#1) showed insusceptibility toward $\mathrm{Km}$ and moderate susceptibilities toward G418 and Hyg. On the other hand, $P$. bambusoides cell line (\#2) expressed strong susceptibilities toward all antibiotics tested. In Hyg condition, $P$. bambusoides cells hardly browned within 3 weeks. Then we investigated the effect of BS and found that the addition of $0.1 \mu \mathrm{M}$ BS clearly suppressed proliferation of bamboo cells without browning (Figure 1(B)). Lower concentration of BS $(<0.1 \mu \mathrm{M})$ did not inhibit cell growth (data not shown). Similar results had been reported in rice calli [5] and Arabidopsis seedlings [2].

\subsection{Transformation of Bamboo Cells}

A portion of suspended cells (ca. $0.5 \mathrm{ml}$ in SCV) was placed in a center of Petri dish which contained the MSp680 medium with $10 \mu \mathrm{M}$ Picloram. The DNAcoated microprojectiles, $498 \mu \mathrm{g}$ gold particles with 0.83 $\mu \mathrm{g}$ DNA were bombarded. The transient $m$ Cherry gene expression was detected at 24 hours after a bombardment as shown in Table 1. We found that pSTARA-RFP worked efficiently in bamboo cells and showed higher transient gene expression (1402 positive cells/dish/shot in average) than that of control pBIH1-RFP (556 positive cells/dish/shot in average) in $P$. nigra cell line under our regular protocol [9]. Then we checked the adaptability of pSTARA-RFP in P. bambusoides cell line and found 491 positive cells/dish/shot in average efficiently expressed mCherry.

During subcultures at 2- to 4-week intervals onto the fresh selection medium supplemented with $0.1 \mu \mathrm{M}$ BS, a large number of BS-resistant cell lines which showed strong expression of $m$ Cherry gene was easily detected (ca. 40 - 100 transformed cell lines/dish/shot were obtained after 4 month of subcultures). This frequency is about the same as pBIH1-RFP in P. nigra [9] and in this experiment. In $P$. bambusoides, however, any resistant cell line could not grow from pBIH1-RFP bombarded cells under the Hyg condition (data not shown). This might be caused by a strong susceptibility to Hyg. In some transformed cell lines strong visible pink fluorescence feature could be seen under the natural light condition as shown in Figure 2. Furthermore, detailed clear cytological images could be observed by using these transformed cells as shown in Figure 3. These results are the evidences that a target transgene will be highly expressed in bamboo cells by pSTARA vector.

\subsection{Stable Expression of $m A L S$ Gene in Bamboo Cells}

Genomic DNA was extracted from 3 randomly selected

Table 1. Transient mCherry gene expression in bamboo suspension cells.

\begin{tabular}{ccc}
\hline Vector & $\begin{array}{c}\text { Number of } m \text { Cherry-expressing } \\
\text { cells/dish/shot }\end{array}$ & Mean \pm SD \\
\hline $\begin{array}{c}\text { pBIH1-RFP } \\
(P . \text { nigra })\end{array}$ & 437 & \\
& 438 & $556 \pm 127$ \\
pSTARA-RFP & 440 & \\
$(P$. nigra $)$ & 948 & $1402 \pm 186$ \\
& 1015 & \\
& 1154 & \\
& 1704 & $491 \pm 85$ \\
pSTARA-RFP & 1735 & \\
$(P$. bambusoides $)$ & 379 & 403 \\
& 440 & \\
\hline
\end{tabular}




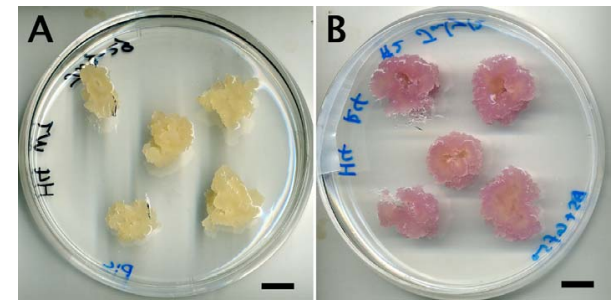

Figure 2. Characteristics of bamboo cultured cells. (A) Nontransformed cell line; (B) Transformed cell line expressing pSTARA-RFP. Scale bars $=1 \mathrm{~cm}$.

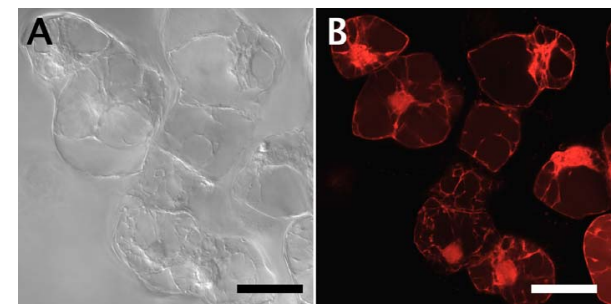

Figure 3. LSM imaging of transformed bamboo cells. The objective lens was a Plan-Apochromat $20 \times 0.8$. (A) Transmitted light; (B): Plane scan; He-Ne laser 543 nm, 15.0\%; Main Beam Splitter: HFT488/543; Beam Splitter 1: mirror; Beam Splitter 2: NFT 545; Filter; LP 560. Scale bars $=50$ $\mu \mathrm{m}$.

independent transformed cells lines as mentioned above and subjected to PCR analysis using gene specific primers for mCherry and $m A L S$. The expected PCR products of each gene were successfully identified (Figure 4).

In order to confirm the expression level of $m A L S$ enzyme in the BS-resistant bamboo cells, we performed an in vivo ALS assay. The assay is based on the colorimetric method which reflects acetoin accumulation depending on the ALS enzyme activity in bamboo cells treated with CPCA with/without BS as follows [2]. Acetolactate synthesized by ALS is subsequently converted to dihydroxyisovalerate by KARI in the branched-chain amino acid biosynthetic pathway. In the presence of CPCA, conversion of acetolactate to dihydroxyiso-valerate is inhibited and acetolactate accumulates in both non-transformed cell line (WT) and transformed cell line (R-4). However, in the presence of both CPCA and BS, the accumulation of acetolactate only occurs in the R-4 cell line harboring $m A L S$ gene as acetolactate synthesis is not affected by BS. The accumulated acetolactate can be converted to acetoin as shown in Figure 5. The endogenous ALS activity of the WT cell line was clearly inhibited by BS. Similar results were obtained in the all PCR-positive cell lines tested.

\section{Conclusion}

Since hygromycin was used for the selection of transformants in monocotyledonous plant species, such as

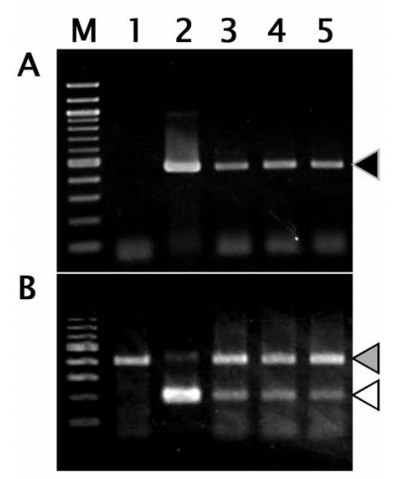

Figure 4. PCR of transformed bamboo cells. M; 100-bp ladder marker, lane 1; non-transformed cell line, lane 2; vector control, lanes 3-5; transformed cell lines. The expected fragments (closed triangle in (A); 468-bp for mCherry, gray triangle in (B); 388-bp for ALS genes, open triangle; 194 and 198-bp for the MfeI digested fragments of amplified $m A L S$ were detected from vector control and genomic DNAs of transformed cells.

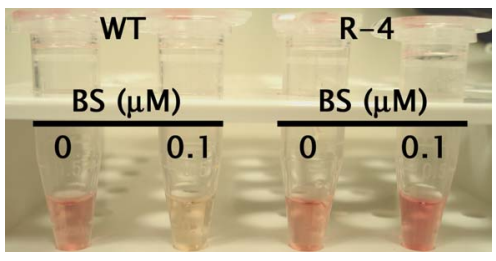

Figure 5. Evaluation of the ALS enzyme activity by in vivo ALS assay. The reddish resultant reaction mixtures indicate acetoin accumulation.

barley [11], rice [12,13], and sugarcane [14], we preliminary investigated the efficacy of $H P T$ gene as a selection marker for transformed bamboo cells [9]. In order to improve transformation technology for engineering/understanding complex biosynthetic pathway(s) of bamboo plants, we described here an illustration of technical details for generating stable transgenic bamboo suspension cells using the particle bombardment method with pSTARA vector harboring the mutated ALS gene derived from rice. In addition, we also informed several advantages of co-expression of $m$ Cherry gene as visible marker with $m A L S$ gene. To the best of our knowledge, this is the first detailed information on the transformation of cultured bamboo cells, both P. bambusoides and $P$. nigra, by adapting $m A L S$ gene from rice. We are certain that these transgenic techniques can be used as a powerful tool for further characterization of physiological and molecular biological events of bamboo species.

\section{Acknowledgements}

This research was supported in part by a Grant-in-Aid for scientific research, C (22580387) from the Japan Society for the Promotion of Science. 


\section{REFERENCES}

[1] K. Kawai, K. Kaku, N. Izawa, A. Fukuda, Y. Tanaka and T. Shimizu, "Functional Analysis of Transgenic Rice Plants Expressing a Novel Mutated ALS Gene of Rice," Journal of Pesticide Science, Vol. 32, No. 4, 2007, pp. 385-392. doi:10.1584/jpestics.G07-08

[2] K. Kawai, K. Kaku, N. Izawa, M. Shimizu, H. Kobayashi and T. Shimizu, "Transformation of Arabidopsis by Mutated Acetolactate Synthase Genes from Rice and Arabidopsis That Confer Specific Resistance to Pyrimidinylcarboxylate-Type ALS Inhibitors," Plant Biotechnology, Vol. 27, No. 1, 2010, pp. 75-84. doi:10.5511/plantbiotechnology.27.75

[3] K. Kawai, K. Kaku, N. Izawa, T. Shimizu, A. Fukuda and Y. Tanaka, "A Novel Mutant Acetolactate Synthase Gene from Rice Cells, Which Confers Resistance to ALS-Inhibiting Herbicides," Journal of Pesticide Science, Vol. 32, No. 2, 2007, pp. 89-98. doi:10.1584/jpestics.G06-40

[4] Y. Wakasa, K. Ozawa and F. Takaiwa, "AgrobacteriumMediated Transformation of a Low Glutelin Mutant of 'Koshihikari' Rice Variety Using the Mutated-Acetolactate Synthase Gene Derived from Rice Genome as a Selectable Marker," Plant Cell Reports, Vol. 26, No. 9, 2007, pp.1567-1573. doi:10.1007/s00299-007-0373-0

[5] Y. Taniguchi, M. Kawata, I. Ando, T. Shimizu and M. Ohshima, "Selecting Genetic Transformants of Indica and indica-Derived Rice Cultivars Using Bispyribac Sodium and a Mutated ALS Gene," Plant Cell Reports, Vol. 29, No. 11, 2010, pp. 1287-1295. doi:10.1007/s00299-010-0915-8

[6] M. Tougou, N. Yamagishi, N. Furutani, K. Kaku, T. Shimizu, Y. Takahata, J. Sakai, S. Kanematsu and S. Hidaka, "The Application of the Mutated Acetolactate Synthase Gene from Rice as the Selectable Marker Gene in the Production of Transgenic Soybeans," Plant Cell Reports, Vol. 28, No. 5, 2009, pp. 769-776. doi:10.1007/s00299-009-0679-1

[7] T. Ogawa, H. Kawahigashi, S. Toki and H. Handa, "Efficient Transformation of Wheat by Using a Mutated Rice Acetolactate Synthase Gene as a Selectable Marker," Plant
Cell Reports, Vol. 27, No. 8, 2008, pp. 1325-1331. doi:10.1007/s00299-008-0553-6

[8] S. Ogita, "Callus and Cell Suspension Culture of Bamboo Plant, Phyllostachys nigra," Plant Biotechnology, Vol. 22, No. 2, 2005, pp. 119-125.

doi:10.5511/plantbiotechnology. 22.199

[9] S. Ogita, N. Kikuchi, T. Nomura and Y. Kato, "A Practical Protocol for Particle Bombardment-Mediated Transformation of Phyllostachys Bamboo Suspension Cells," Plant Biotechnology, Vol. 28, No. 1, 2011, pp. 43-50. doi:10.5511/plantbiotechnology. 10.1101a

[10] S. Ohta, S. Mita, T. Hattori and K. Nakamura, "Construction and Expression in Tobacco of a $\beta$-Glucuronidase (GUS) Reporter Gene Containing an Intron within the Coding Sequence," Plant and Cell Physiology, Vol. 31, No. 6, 1990, pp. 805-813.

[11] M. O. Um, T. I. Park, Y. J. Kim, H. Y. Seo, J. G. Kim, S. Y. Kwon, S. S. Kwak, D. J. Yun and S. J. Yun, "Particle bombardment-Mediated Transformation of Barley with an Arabidopsis NDPK2 cDNA," Plant Biotechnology Reports, Vol. 1, No. 2, 2007, pp. 71-77. doi:10.1007/s11816-007-0016-5

[12] Y. Hiei, S. Ohta, T. Komari and T. Kumashiro, "Efficient Transformation of Rice (Oriza sativa L.) Mediated by Agrobacterium and Sequence Analysis of the Boundaries of the T-DNA," The Plant Journal, Vol. 6, No. 2, 1994, pp. 271-282. doi:10.1046/j.1365-313X.1994.6020271.x

[13] D. Sudhakar, L. T. Duc, B. B. Bong, P. Tinjuangjun, S. B. Maqbool, M. Valdez, R. Jefferson and P. Christou, "An Efficient Rice Transformation System Utilizing Mature Seed-Derived Explants and a Portable, Inexpensive Particle Bombardment Device," Transgenic Research, Vol. 7, No. 4, 1998, pp. 289-294. doi:10.1023/A:1008870012568

[14] A. D. Arencibia, E. R. Carmona, P. Tellez, M. T. Chan, S. M. Yu, L. E. Trujillo and P. Oramas, "An Efficient Protocol for Sugarcane (Saccharum spp. L.) Transformation Mediated by Agrobacterium tumefaciens," Transgenic Research, Vol. 7, No. 3, 1998, pp. 213-222. doi:10.1023/A:1008845114531 